\title{
Persebaran Agens Hayati Neochetina spp. (Coleoptera: Curculionidae) Di Jawa Barat Dan DKI Jakarta
}

\section{SAPDI, D. BUCHORI, U. KARTOSUWONDO, S. TJITROSEMITO DAN B. SAHARI}

\author{
Alumnus Program S3,Program Studi Entomologi-Fitopatologi , IPB \\ Jl. Kamper, Kampus Darmaga, IPB, Bogor
}

(diterima September 2005, disetujui Februari 2006)

\begin{abstract}
The Distribution of Biocontrol Agents Neochetina spp. (Coleoptera: Curculionidae) in West Java and DKI Jakarta. The establishment of Neochetina spp. as biocontrol agent of waterhyacinth are related to the weevil's ability to disperse and to increase their population sizes. The objective of this research was to study the distribution and abundance of Neochetina spp. at several areas in West Java and DKI Jakarta. The field research was done in several freshwater ecosystem infested by waterhyacinth, including Cibinong and Lido lakes in Bogor, irigation canal in Karawang, Muara Angke Sanctuary in North Jakarta, and Citarum Hulu river in Purwakarta, during April to August 2004. Coordinate and elevation of the research sites where $N$. eichborniae and $N$. bruchi found were reported, while their abundances were observed by direct hand-collection technique. The results of the research showed that $N$. eichhorniae was widely distributed and established in most sampling sites, except in Karawang, whereas N. bruchi was not found in any sampling sites. Our observations also indicated that N. eichhorniae was distributed passively so that the weevil couldn't colonize isolated habitats or locations.
\end{abstract}

KEY WORDS: Neochetina spp., waterhyacinth, biological control, invasivesp.

\section{PENDAHULUAN}

Pemanfaatan kumbang moncong, Neochetina spp. (Coleoptera: Curculionidae) sebagai agens pengendali hayati eceng gondok telah banyak dilakukan (Grodowitz 1998; Kasno et al. 2001; Ochiel et al. 2001; Fayad et al. 2001). Di Indonesia, pengendalian hayati eceng gondok menggunakan agens hayati ini telah dikembangkan sejak tiga dekade yang lalu (Kasno et al. 2001). Kegiatan ini dimulai dengan diintroduksinya dua spesies Neochetina yaitu N. eichhorniae Warner pada tahun 1975 (Subagyo et al.
1977) dan N. bruchi Hustache pada tahun 1994 (Widayanti et al. 1999).

Setelah suatu agens pengendalian hayati gulma dilepas di alam terbuka, tidak berarti kegiatan pengendalian hayati telah selesai, tetapi masih harus diikuti dengan kegiatan pemantauan dan evaluasi (Kasno 2003). Kegiatan ini sangat diperlukan untuk mengetahui sejauh mana kemapanan agens hayati introduksi tersebut pada ekosistem yang baru. Demikian juga halnya dengan introduksi Neochetina spp. sebagai agens hayati eceng gondok. Tingkat kemapanan 
agens hayati ini sangat berhubungan dengan kemampuannya untuk menyebar dan meningkatkan populasinya.

Dalam dua puluh tahun terakhir, kebanyakan penelitian di Indonesia terfokus pada pengembangan metode pembiakan massal dalam upaya pemanfaatan $N$. eichborniae dan $N$. bruchi untuk mengendalikan eceng gondok. Sayang nya, belum banyak dilakukan upaya monitoring secara terencana untuk mengevaluasi sejauh mana kemapanan agens hayati introduksi tersebut setelah dilepaskan di lapangan. Spesies mana diantara kedua spesies agens hayati tersebut yang telah mapan di lapangan, serta bagaimana perkembangan populasinya juga tidak diketahui.

Bertitik tolak pada uraian di atas, maka perlu dilakukakan evaluasi terhadap penyebaran dan kelimpahan individu Neochetina spp. di lapangan, terutama untuk daerah Jawa Barat yang merupakan titik pelepasan agens hayati tersebut. Oleh karena itu, penelitian ini bertujuan untuk mempelajari persebaran Neochetina spp. di beberapa daerah di Jawa Barat dan DKI Jakarta, serta kelimpahan individu agens hayati tersebut dan fluktuasinya di lapangan.

\section{BAHAN DAN METODE}

\section{Tempat dan Waktu Penelitian}

Penelitian ini dilakukan pada beberapa ekosistem perairan di Jawa Barat dan DKI Jakarta. Lokasi pengambilan sampel ditentukan berdasarkan purposive sampling methode, yaitu meliputi ekosistem perairan yang terinfestasi eceng gondok. Dari hasil survey pendahuluan maka ditetapkan lima lokasi penelitian, yaitu: Danau Cibinong, saluran irigasi di Karawang, Danau Lido, Suaka Margasatwa Muara Angke, dan sungai Citarum Hulu di Purwakarta. Pengambilan sampel berlangsung sejak April hingga Agustus 2004.

\section{Pelaksanaan Penelitian}

\section{Persebaran Neochetina spp.}

Pengamatan terhadap persebaran Neochetina spp. dilakukan dengan melihat keberadaan agens hayati tersebut pada eceng gondok di lima lokasi yang telah ditetapkan. Setiap lokasi yang ditemukan N. eichhorniae dan N. bruchi dicatat altitude, latitude, dan longitude nya.

\section{Kelimpahan individu Neochetina spp.}

Koleksi imago Neochetina spp. dilakukan secara manual dengan tangan (hand colection). Untuk setiap lokasi, koleksi kumbang dilakukan pada petak kuadrat berukuran $1 \mathrm{~m}^{2}$, dengan 5 kali ulangan. Jarak antar petak sampel \pm 10 m. Jumlah imago yang ditemukan pada setiap petak sampel dihitung berdasarkan jenis kelaminnya. Selain itu, pengamatan juga dilakukan terhadap kelimpahan individu larva. Rara-rata jumlah larva dihitung pada 10 rumpun eceng gondok yang diambil secara diagonal dari setiap petak sampel. Pengamatan terhadap kelimpahan individu imago di- 
lakukan setiap bulan hingga 5 kali (AprilAgustus 2004), sedangkan kelimpahan individu larva hanya diamati sekali (Juli 2004).

\section{Analisis Data}

Untuk melihat signifikansi perbedaan kelimpahan individu imago dan larva Neochetina spp. antar lokasi, di analisis menggunakan ANOVA satu arah (one-way ANOVA) dan Uji Jarak Berganda Duncan (DMRT) pada selang kepercayaan 95\% dengan program Statistica for Windows 6.0. Analisis yang sama juga digunakan untuk melihat signifikansi perbedaan kelimpahan individu imago kumbang tersebut antar waktu pengamataan dan intensitas kerusakan daun eceng gondok antar lokasi.

\section{HASIL DAN PEMBAHASAN}

\section{Hasil}

\section{Penyebaran Neochetina spp.}

Hasil penelitian menunjukkan bahwa Neochetina spp. telah menyebar luas di wilayah Jawa Barat dan DKI Jakarta. Hampir pada semua lokasi penelitian ditemukan agens hayati tersebut, kecuali di Karawang. Dari keseluruhan kumbang yang ditemukan diidentifikasi sebagai Neochetina eichhorniae, sedangkan N. bruchi tidak ditemukan pada penelitian ini (Tabel 1).

\section{Kelimpahan Individu Neochetina spp.}

Kelimpahan individu imago $N$. eichborniae secara keseluruhan berbeda nyata antar lokasi. Perbedaan yang nyata terlihat baik dalam jumlah imago per $\mathrm{m}^{2}$ $\left(\mathrm{F}_{3,16}=11,249 ; \mathrm{p}<0,001\right)$ maupun jumlah imago per rumpun eceng gondok $\left(\mathrm{F}_{4,20}=9,847 ; \mathrm{p}<0,001\right)$ (Gambar 1). Secara umum terlihat bahwa kelimpahan individu imago $N$. eichhorniae dijumpai di dataran tinggi (Cibinong, Muara Angke, dan Purwakarta) lebih tinggi daripada di dataran rendah (Lido).

Kelimpahan individu larva yang di amati pada bulan Juli 2004 juga berbeda nyata antar lokasi $\left(\mathrm{F}_{3,16}=22,210 ; \mathrm{p}<\right.$ 0,001). Demikian juga dengan kelimpahan individu imago yang diamati pada bulan yang sama $\left(\mathrm{F}_{3,16}=21,049 ; \mathrm{p}<\right.$ $0,001)$ dan bulan Agustus $2004\left(\mathrm{~F}_{3,16}=\right.$ 9,635; $\mathrm{p}<0,001)$ (Tabel 2).

Tabel 1. Eksistensi Neochetina eichhorniae dan N. bruchi di lima lokasi penelitian

\begin{tabular}{lcccc}
\hline \hline Lokasi & \multicolumn{1}{c}{ Koordinat } & Ketinggian & N. eichhorniae & N. bruchi \\
\hline Cibinong & $06,469^{\circ} \mathrm{LS}, 106,858^{\circ} \mathrm{BT}$ & $117 \mathrm{~m}$. dpl. & + & - \\
Karawang & $06,263^{\circ} \mathrm{LS}, 107,591^{\circ} \mathrm{BT}$ & $37 \mathrm{~m} . \mathrm{dpl}$. & - & - \\
Lido & $06,736^{\circ} \mathrm{LS}, 106,808^{\circ} \mathrm{BT}$ & $512 \mathrm{~m} . \mathrm{dpl}$. & + & - \\
Muara Angke & $06,115^{\circ} \mathrm{LS}, 106,767^{\circ} \mathrm{BT}$ & $28 \mathrm{~m} . \mathrm{dpl}$. & + & - \\
Purwakarta & $06,507^{\circ} \mathrm{LS}, 107,392^{\circ} \mathrm{BT}$ & $56 \mathrm{~m} . \mathrm{dpl}$ & + & - \\
\hline
\end{tabular}


Sapdi et al.,: Persebaran Agens Hayati Neochetina spp.

Kelimpahan individu imago $N$. imago $N$. eichhorniae juga mengeichhorniae di semua lokasi penyebaran gambarkan kelimpahan individu larva. berfluktuasi secara temporal, tetapi pola Hal ini ditunjukkan oleh adanya korelasi nya tidak konsisten dan tidak berbeda positif yang nyata antara kelimpahan innyata $\left(F_{4,15}=0,287 ; p=0,882\right)$ (Gambar dividu larva agens hayati tersebut dengan 2). Fluktuasi kelimpahan individu kum- kelimpahan individu imagonya ( $\mathrm{r}=$ bang tersebut yang agak tinggi terjadi di 0,863; p < 0,001) (Gambar 3). Rata-rata Muara Angke dan Cibinong, sedangkan kelimpahan individu larva lebih tinggi di Purwakarta dan Lido relatif stabil.

dibandingkan kelimpahan individu ima-

Secara umum kelimpahan individu go, sebagaimana terlihat pada Tabel 2.
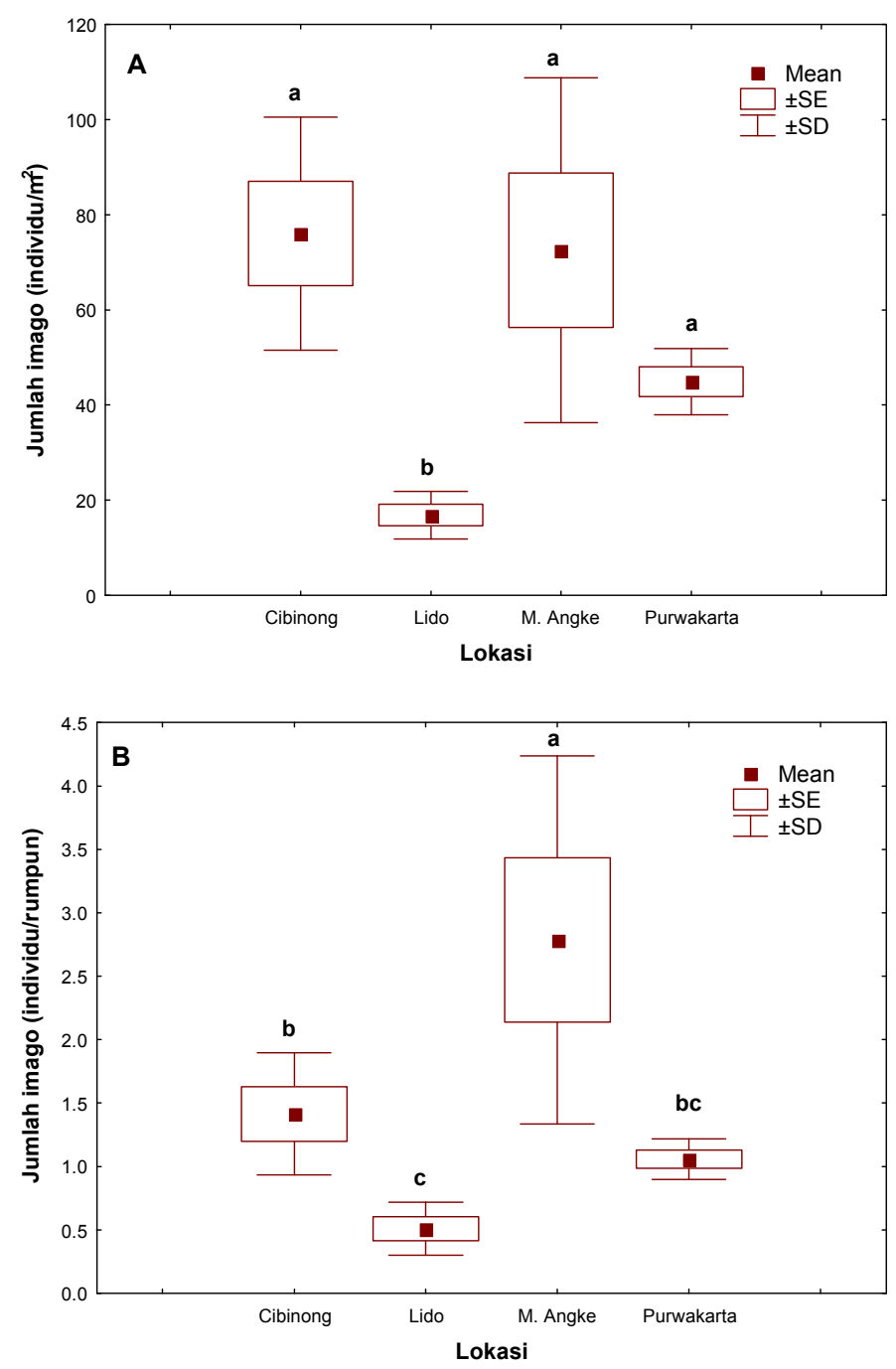

Gambar 1. Kelimpahan individu imago Neochetina eichhorniae per $m^{2}$ (A) dan per rumpun eceng gondok (B) di empat lokasi penelitian (huruf yang sama pada gambar yang sama menunjukkan tidak berbeda nyata pada taraf 0,05 , DMRT). 
Hasil pengamatan terhadap komposisi imago berdasarkan jenis kelamin menunjukkan bahwa persentase betina, baik secara total, rata-rata, maupun per bulan selama pengamatan relatif sama, yaitu mendekati 40\% (Tabel 3). Dengan kata lain, perbandingan antara imago betina dan jantan adalah mendekati 2:3.

\section{Pembahasan}

Hasil penelitian mengindikasikan bahwa $N$. eichhorniae dapat berkembangbiak di lapangan, sebaliknya $N$. bruchi tidak mampu mencapai kemapanan. Ketidakmapanan N. bruchi diduga terjadi karena kegagalan adaptasi spesies tersebut, bukan akibat terjadinya kompetisi interspesifik. Center et al. (2002) menyatakan bahwa kecil kemungkinan terjadi kompetisi interspesifik antara $N$. eichborniae dan N. bruchi, sebab kedua spesies tersebut memiliki perilaku yang berbeda, misalnya preferensi untuk tempat peletakan telur. Selain itu, Ochiel et al. (2001) juga melaporkan bahwa kedua spesies agens hayati tersebut samasama telah mapan di Danau Victoria, Kenya.

Data yang diperoleh dari penelitian ini juga mengindikasikan bahwa Neochetina spp. lebih efektif menyebar secara pasif dibandingkan secara aktif. Hal ini ditunjukkan oleh ketidakmampuan kumbang ini mengkoloni hamparan eceng gondok yang terisolasi, yaitu di Karawang. Hasil ini mendukung beberapa penelitian sebelumnya. Jianqing (2002) melaporkan bahwa di beberapa sungai di Wenzhou, Provinsi Zhejiang, Cina, kumbang ini dapat menyebar dengan eceng gondok yang hanyut melalui aliran sungai hingga $40 \mathrm{~km}$ dari titik pelepasan, dalam kurun waktu 4 tahun. Sementara itu, perpindahan aktif terutama terjadi dalam hamparan eceng gondok yang hanya mencapai 100,8 cm dalam periode 15 hari (Tjitrosoedirdjo $e t$ al. 2003).

Tabel 2. Kelimpahan individu larva dan imago Neochetina eichhorniae di empat lokasi pengambilan sampel

\begin{tabular}{lccc}
\hline \hline \multirow{2}{*}{ Lokasi } & \multicolumn{3}{c}{ Rata-rata kelimpahan individu/rumpun \pm SD } \\
\cline { 2 - 4 } & Larva (Juli 2004) & Imago (Juli 2004) & Imago (Agustus 2004) \\
\hline Cibinong & $2,12 \pm 0,40 \mathrm{~b}$ & $1,74 \pm 0,47 \mathrm{~b}$ & $1,86 \pm 0,41 \mathrm{a}$ \\
Lido & $1,15 \pm 0,20 \mathrm{~cd}$ & $0,85 \pm 0,15 \mathrm{~b}$ & $0,44 \pm 0,19 \mathrm{c}$ \\
Muara Angke & $5,91 \pm 2,06 \mathrm{a}$ & $4,85 \pm 1,75 \mathrm{a}$ & $1,49 \pm 0,72 \mathrm{ab}$ \\
Purwakarta & $1,29 \pm 0,27 \mathrm{bc}$ & $0,90 \pm 0,25 \mathrm{~b}$ & $1,02 \pm 0,22 \mathrm{bc}$ \\
\hline
\end{tabular}

Keterangan: Angka yang diikuti huruf yang sama pada kolom yang sama menunjukkan tidak berbeda nyata pada taraf 0,05 (DMRT) 
Sapdi et al.,: Persebaran Agens Hayati Neochetina spp.

Berdasarkan kelimpahan individu imago $N$. eichhorniae terlihat bahwa kelimpahan agens hayati ini di dataran rendah lebih tinggi daripada di dataran tinggi. Hal ini diduga berkaitan dengan cara penyebaran kumbang tersebut yang lebih banyak bersifat pasif mengikuti pergerakan massa eceng gondok dari dataran tinggi ke dataran rendah. Indikasi ini terlihat dengan tingginya kelimpahan $N$. eichborniae di Muara Angke, yang diduga disebabkan oleh tingginya pergerakan massa eceng gondok melalui sungai yang bermuara ke wilayah tersebut. Sementara itu, tidak ditemukannya agens hayati tersebut di Karawang, yang merupakan lokasi yang sangat terisolasi karena adanya hamparan persawahan yang luas, telah memperkuat dugaan bahwa penyebaran kumbang tersebut lebih bersifat pasif.

Ada fenomena menarik yang teramati pada fluktuasi kelimpahan individu imago N. eichhorniae di Muara Angke dan Cibinong. Di Muara Angke, kelimpahan imago agens hayati tersebut menurun drastis pada bulan Agustus 2004, padahal kelimpahannya cukup tinggi pada bulan Juli 2004 (Gambar 2).
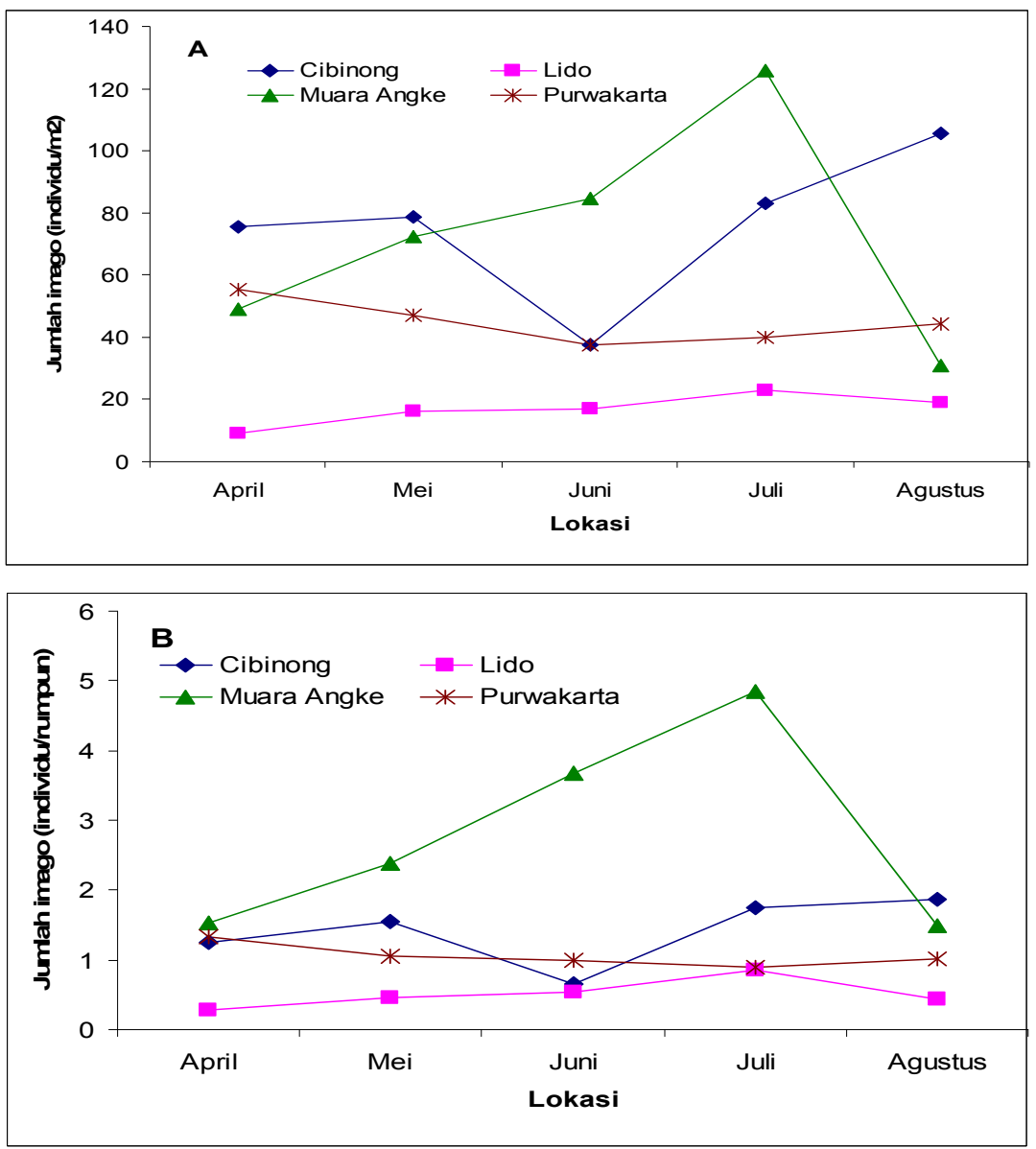

Gambar 2. Fluktuasi kelimpahan individu imago $N$. eichhorniae per $\mathrm{m}^{2}$ (A) dan per rumpun eceng gondok (B) di empat lokasi (April - Agustus 2004). 
Hal ini diduga disebabkan oleh terjadinya kematian massal eceng gondok pada pertengahan bulan Juli, sebagai akibat pasang air laut yang menggenangi hamparan eceng gondok. Sementara itu, di danau Cibinong dilakukan pembersihan selektif terhadap eceng gondok yang sudah besar pada bulan Juni sehingga kelimpahan individu yang teramati pada bulan tersebut lebih rendah daripada bulan-bulan lainnya.

Ada kecenderungan bahwa kelimpahan individu larva $N$. eichhorniae di lapangan lebih tinggi dibandingkan kelimpahan individu imagonya. Data ini mirip dengan hasil penelitian Kasno et al. (2001) yang melaporkan bahwa kelimpahan larva N. eichborniae di Danau Situbagendit pada bulan Juni dan Agustus 1998 relatif lebih tinggi daripada kelimpahan imagonya. Hal ini diduga berkaitan dengan pola reproduksi $N$. eichhorniae yang dapat terjadi sepanjang tahun (Center 1994), sehingga dapat diprediksi bahwa komposisi setiap fase pertumbuhan kumbang tersebut di lapangan relatif stabil.

Berdasarkan hasil yang diperoleh

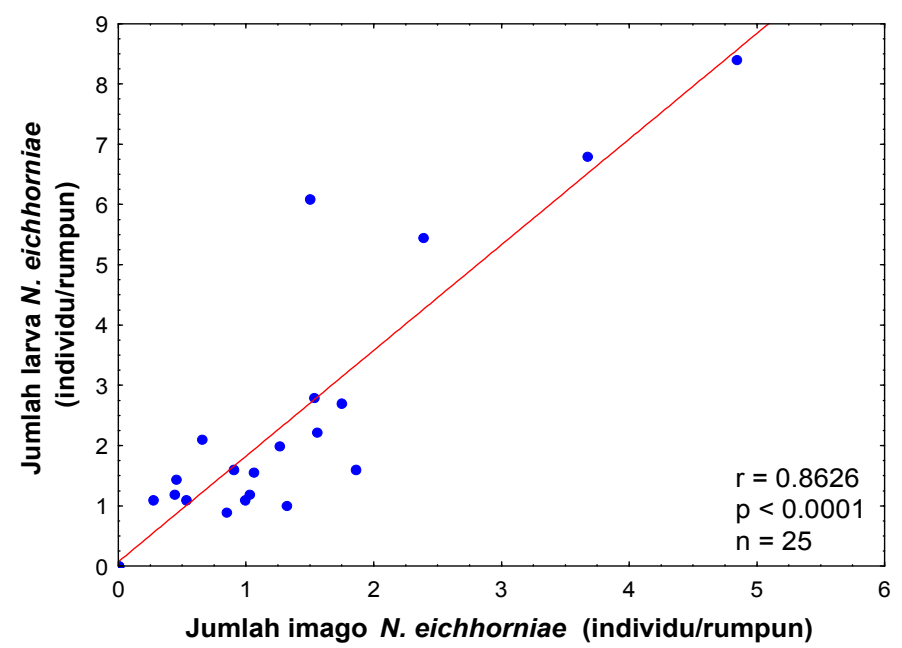

Gambar 3. Korelasi antara kelimpahan individu imago dan larva Neochetina eichhorniae yang ditemukan di empat lokasi penelitian.

Tabel 3. Fluktuasi kelimpahan individu imago $N$. eichhorniae per $\mathrm{m}^{2}(\mathrm{~A})$ dan per rumpun eceng gondok (B) di empat lokasi (April - Agustus 2004).

\begin{tabular}{lccccc}
\hline \hline \multirow{2}{*}{$\begin{array}{l}\text { Persentase } \\
\text { betina }\end{array}$} & \multirow{2}{*}{$\begin{array}{c}\text { Bulan } \\
(2004)\end{array}$} & \multicolumn{5}{c}{ Lokasi } \\
\cline { 3 - 6 } & 4 & $41,23 \pm 4,23$ & $38,65 \pm 16,40$ & $40,84 \pm 6,38$ & $37.24 \pm 3.62$ \\
\hline Per bulan & 5 & $40,12 \pm 0,62$ & $37,73 \pm 4,20$ & $38,35 \pm 3,85$ & $39.24 \pm 8.16$ \\
& 6 & $40,03 \pm 6,15$ & $35,60 \pm 10,13$ & $37,02 \pm 4,96$ & $40.31 \pm 13.67$ \\
& 7 & $37,26 \pm 1,20$ & $38,26 \pm 5,56$ & $41,26 \pm 4,24$ & $36.82 \pm 2.17$ \\
& 8 & $40,14 \pm 4,49$ & $38,97 \pm 8,48$ & $39,28 \pm 6,28$ & $33.84 \pm 4.78$ \\
\hline Rata-rata & & $39.75 \pm 1.48$ & $37,84 \pm 1,33$ & $39,35 \pm 1,76$ & $37,49 \pm 2,49$ \\
\hline Total & & $39.75 \pm 3.84$ & $37,84 \pm 9,14$ & $39,35 \pm 5,05$ & $37,49 \pm 7,36$ \\
\hline
\end{tabular}


pada penelitian ini dapat dikatakan bahwa kelimpahan individu N. eichhorniae yang ditemukan sangat rendah (rata-rata kurang dari 3 individu per rumpun) dibandingkan dengan yang ditemukan di Danau Victoria, Uganda. Ogwang (2001) melaporkan bahwa selama tahun 1997, pada hamparan eceng gondok ditemukan rata-rata 25 individu per rumpun pada beberapa bagian Danau Victoria. Rendahnya kelimpahan $N$. eichborniae di Indonesia pada umumnya diduga disebabkan oleh tingginya mortalitas pupa. Perbedaan populasi larva dan imago sebesar $17 \%$ hingga 30\% (Tabel 2) mengindikasikan adanya mortalitas pada stadium pupa. Angka tersebut diduga lebih tinggi daripada yang teramati sebab ada kemungkinan sebagian larva tidak teramati, terutama larva-larva instar awal.

Mortalitas pupa juga terungkap dari hasil penelitian Kasno et al. (2001) yang melaporkan bahwa banyak pupa yang mati karena dimakan oleh ikan predator. Selain itu, bebek juga diketahui dapat berperan sebagai predator larva, pupa, bahkan imago N. eichborniae (Sukisman; komunikasi pribadi). Widayanti et al (1999) juga menemukan bahwa laba-laba serigala (wolf spider) memangsa larva N. bruchi. Kendala pertumbuhan populasi agens hayati ini juga dapat berupa penyakit yang disebabkan oleh patogen, antara lain misalnya microsporidia. Rebelo dan Center (2001) melaporkan bahwa penyakit yang disebabkan oleh mikrosporidia biasanya bersifat kronis tanpa manifestasi gejala eksternal pada inangnya. Pengaruh subletal infeksi mikrosporidia pada $N$. eichhorniae dapat menurunkan fertilitas sebesar 46,2\% dan lama hidup sebesar $41,8 \%$.

Selain mortalitas larva, pupa dan imago, nisbah kelamin imago $N$. eichhorniae merupakan salah satu faktor yang menyebabkan rendahnya laju pertumbuhan populasi kumbang tersebut. Perbandingan antara imago betina dan jantan yang diperoleh dalam penelitian ini, yang mendekati 2:3, berbeda dengan laporan Julien et al. (1999) yang menemukan bahwa di California, rasio antara betina dan jantan adalah 1:1. Proporsi imago betina yang lebih rendah daripada jantan berpengaruh negatif terhadap perkembangan populasi agens hayati tersebut.

Berdasarkan hasil pengamatan terhadap persentase betina N. eichhorniae, yang selalu satabil dari waktu ke waktu, dapat diasumsikan bahwa jumlah telur yang diletakkan relatif stabil. Dengan demikian dapat diasumsikan juga bahwa larva yang dihasilkan akan selalu sebanding dengan populasi imago. Fakta ini dapat menjelaskan mengapa populasi kumbang tersebut di lapangan dari waktu ke waktu relatif tidak berfluktuasi. Hasil yang sama juga ditemukan dari penelitian di Amerika Serikat yang menunjukkan bahwa imago N. eichornia dan N. bruchi dapat bereproduksi sepanjang tahun, tanpa perbedaan generasi (Center 1994). 


\section{KESIMPULAN}

Neochetina eichhorniae telah menyebar luas di wilayah Jawa Barat dan DKI Jakarta, kecuali di Karawang. Spesies N. bruchi tidak ditemukan pada penelitian ini. Penyebaran N. eichhorniae secara pasif lebih efektif dibandingkan secara aktif sehingga habitat yang terisolasi tidak dapat dikolonisasi oleh agens hayati ini.

Kelimpahan individu N. eichhorniae di dataran rendah lebih tinggi daripada di dataran tinggi. Kelimpahan individu agens hayati ini secara temporal relatif tidak berfluktuasi. Meskipun $N$. eichborniae telah mapan di lapangan, namun kelimpahannya sangat rendah.

\section{UCAPAN TERIMA KASIH}

Tulisan ini merupakan bagian dari Disertasi penulis pertama. Penulis menyampaikan penghargaan dan terima kasih atas dukungan dana Penelitian dari Wildlife Trust, melalui Yayasan Peduli Konservasi Indonesia (PEKA), dan Hibah Penelitian Tim Pascasarjana (HPTP) Angkatan II Tahun 2004-2006.

\section{DAFTAR PUSTAKA}

Center TD. 1994. Biological control of weeds: waterhyacinth and waterlettuce. Di dalam: Rosen D, Bennet FD, Capinera JL, editor. Pest management in the subtropics: Biological control-a Florida perspective. Intercept Ltd, Andover, UK.

Center TD, Hill MP, Cordo H, Julien MH. 2002. Waterhyacinth. Dalam: Van Driesche R et al. Biological control of invasive plants in the Eastern United States. USDA Forest Service Publication FHTET.
Fayad YH, Ibrahim AA, El-Zoghby AA, Shalaby FF. 2001. Ongoing activities in the biological control of waterhyacinth in Egypt. Dalam Julien, M.H., Hill, M.P., Center, T.D., and Jianqing, D. (Eds). Biological and Integrated Control Of Water Hyacinth, Eichhorniae crassipes. ACIAR Proceedings 102. hal 43-46.

Grodowitz MJ. 1998. An active approach to the use of insect biological control for the management of non-native aquatic plants. J Aquat. Plant Manage. 36: 57-61.

Jianqing D. 2002. The invation of waterhyacint in China. Di dalam: IMPECCA. Biological and Integrated Control Of Eichhornia crassipes. Water Hyacinth News No. 5. CABI Bioscience, Silwood Park, UK.

Julien MH, Griffiths MW, Wright AD. 1999. Biological Control of Water Hyacinth. The weevils Neochetina bruchi and Neochetina eichhorniae: biologies, host ranges, releasing and monitoring techniques for biological control of Eichhornia crassipes. ACIAR, Canbera.

Kasno. 2003. Pengendalian gulma secara biologis. J Tropical Weeds1(1): 13-17.

Kasno, Putri ASR, Widayanti S, Sunjaya. 2001. Establisment of Neochaetina sp.: Their pattern of local dispersal and age structure at release site. BIOTROPIA 13:18-29.

Ochiel GS, Njoka SW, Mailu AM, Gitonga W. 2001. Establishment, spread and impact of Neochetina spp. on water hyacinth in Lake Victoria, Kenya. Dalam Julien MH, Hill, MP, Center TD, Jianqing D. (Eds). Biological and Integrated Control Of Water Hyacinth, Eichhornia crassipes. ACIAR Proceedings 102. hal 89-95.

Ogwang J. 2001. Is there resurgence on Lake Victoria? Dalam IMPECCA. Biological and integrated control of Eichhornia crassipes. Water Hyacinth News No. 4. CABI Bioscience, Silwood Park, UK.

Rebelo MT, Center TD. (2001). Microsporidia \& Neochetina. Di dalam: IMPECCA. Biological and integrated control of Eichhornia crassipes. Water Hyacinth News No. 4. CABI Bioscience, Silwood Park, UK.

Subagyo T, Kasno, Mangoendihardjo S. 1977. Masalah dan pengendalian tumbuhan pengganggu air Rawa Pening. Laporan Akhir 1976-1977. SEAMEO BIOTROP, Bogor. 
Sapdi et al.,: Persebaran Agens Hayati Neochetina spp.

Tjitrosoedirdjo SS, Kasno, Tjitrosemito S. 2003. The biological control of water hyacinth in Indonesia. J Tropical Weeds1(1): 18-23.

Widayanti S, Kasno, Tjitrosoedirdjo SS, Tjitrosemito S. 1999. Efforts in using water hyacinth weevils to control water hyacinth in Indonesia. Dalam Proceedings of The Workshop on Integrated Weed Management in Managed and Natural Ecosystem. Bogor, 23-25 Juni 1998. BIOTROP Special Publication 61: 163-171. 